\title{
A TEST OF AN OTTO GAS ENGINE.
}

Edgar KidWhll and Edwin R. Kellek.

[Contributed by the Mechanical Engineering Department of the University of Pinnsylvania.]

The following article is an abstract of a test made by Messrs. Kidwell and Keller for a graduating thesis in the Department of Mechanical Engineering.

The engine had been in use for a long time without overhauling by the makers, but was in fair average condition. The admirable set of experiments, conducted under the auspices of the Society of Arts, the results of which were published after these experiments were made, seemed to make it unnecessary to publish the entire record and work of the test, but as some of the results are worked out in a somewhat different way, a short account of the test and its results may be of interest.

$$
\begin{aligned}
& \text { H. W. SPAngler, U. S. Navy, } \\
& \text { Asst. Prof. Mech'l Eng'r'g. }
\end{aligned}
$$

\section{METIODS.}

The engine experimented on was a seven horse-power (nomina1) Otto type engine. The volume of the cylinder and clearance space was determined by filling with water and found to be 439 cubic feet for the total volume, and - 796 cubic feet for the clearance space, leaving ·2594 cubic feet for the volume swept through by the piston each stroke.

The gas used during the test was passed through a large meter, and thence through rubber bags to the cylinder, a portion passing through a second meter, being taken from the same supply for the jet.

The pressure of the gas used was taken by a manometer, attached to the supply pipe, and the absolute pressure of the gas was found by adding to this reading that of the standard signal service barometer. The temperature of the 
gas was taken as that of the room, the meter, bags and pipes being practically entirely within the room. Samples of the gas were taken for analysis. The amount of cooling water used was weighed, by allowing it to discharge in a vessel for periods of ten minutes during the test, the water running at practically the same quantity per minute throughout the entire test. The temperature of the water before and after leaving the cylinder jacket was taken by themometers placed as shown in Fig. $I$, which also shows the position of a Brown's pyrometer placed in the exhaust pipe of the engine. The length of pipe between the cylinder and pyrometer was carefully covered with asbestos board, preventing radiation to a great extent.

The power developed in the cylinder during each explosion was determined from a mean indicator card constructed as described below, the power given off by the engine being absorbed by a friction brake on the fly-wheel.

The speed was taken every five minutes by a revolution counter and stop-watch.

It was found necessary to limit the duration of the tests to one hour at a time because of the heating of the flywheel. The engine was started and allowed to run an hour; the brake was then put on, and after the engine had settled down to steady condition the test began. It was continued for an hour, the brake was removed, and the engine kept running until the wheel cooled down, when the brake was replaced and another set of observations made. The total duration of the tests, that is, the actual time during which the observations were made, was three hours, ten minutes.

APPARATUS.

The thermometers used were made by Henry J. Green, of New York, and read to degrees Fahrenheit. The pyrometer used was made by Edw. Brown, of Philadelphia, and was graduated at intervals of $10^{\circ}$ to $1,200^{\circ} \mathrm{F}$. The revolution cointer used was of the endless-screw and wheel type, reading to single revolution. The stop-watch read to one-fifth second. The meters used were a large one, made by the Goodwin Meter Company, for gas-engine tests, and 
an ordinary seven-light moter made by the same company. The scales for weighing the water read to $\frac{1}{100}$ pound.

The apparatus used for analyzing the gas was an Elliott apparatus, similar to that $11 \mathrm{sed}$ at the International Electrical Exhibition in 1884 .

A Crosby indicator, with a Ioo-pound spring, was used throughout the test.

The bulbs of the thermometers used for measuring the temperature of the jacket water were inserted in thin metal cups screwed into the pipe comnections, as shown in Fig. $I$, the lower one being kept full of water, and the upper one of oil.

The following are some of the results of the test:

Date, January 19, 1889 .

Time of test. . . . . . . . . . 3 hrs. $10 \mathrm{~m}$.

Temperature gas, . . . . . . . . . . . . . $62^{\circ} 2$

Temperature of exhaust, . . . . . . . . . . . $774^{\circ .28}$

Temperature of entering water, . . . . . . . . . $50^{\circ} 43$

Temperature of exit water, . . . . . . . . . . . $89^{\circ} 19$

Manometer, inches water, . . . . . . . . . . . 3.06

Barometer (reduced to pounds), . . . . . . . . . 14.85

Total gas used, cubic feet, . . . . . . . . . . . 344.4

Gas for ignition, . . . . . . . . . . . . . . 9.625

Average revolutions per minute, . . . . . . . . 161.6

Explosions missed per minute, . . . . . . ... . 6.83

\section{COMPUTATION.}

As the test was rather for determining the distribution of the head developed by burning the gas, or for getting data for determining its efficiency as a heat engine rather than as a machine, and as the observing force was limited, the brake horse-power was not taken.

The indicator cards were worked up in the following way. $F i g .2$ is a mean card obtained as follows: On each of the forty-two cards taken, twenty-eight lines were drawn at right angles to the atmospheric line as shown, and the pressure of the bottom and top of each card was read and tabulated. From the mean of these tabulated values, the card shown in the figure was drawn. From this card the horse-power was calculated as follows:

Nean pressure for card $=59$ pounds. 
Mean pressure per foot $=59 \times 144$ pounds.

Value of stroke in feet $=2594$.

Work per explosion $=59 \times \mathrm{r} 44 \times 2594 \mathrm{ft}$. pounds.

Explosion per minute $=\frac{161^{\circ} 6}{2}-6.83=73.97$.

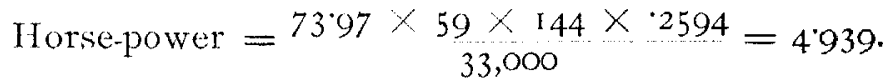

It will be noticed that the exhaust and admission parts of the diagram are omitted as they practically coincided with the atmospheric line.

In addition to finding the work done, the mean card was used to determine the general equation of the expansion, compression and explosion part of the diagram.

In determining these curves the part between ordinates (8) and (28) was taken for the compression curve in the calculation; the explosion curve was taken to embrace all the upper curve between (23) and (28); and the expansion curve was taken to cover all the upper curves betwecn (5) and (18).

The expansion and compression curves were assumed to vary according to a law $p a^{n}=c$, in which $p$ is the pressure in pounds per square inch, and $v=$ the volume in cubic feet of the mixture, while $c$ and $n$ are constants. By taking the values of $p$ and $i$, as given on the mean indicator card by the method of Least Squares, the most probable values of $n$ and $c$ were determined.

The equation to the curve of expansion was found to be

$$
p v^{1 \cdot 4385}=15.901
$$

and for the compression curve was found to be-

$$
p v^{1 \cdot 5313}=3 \cdot 7557 \text {. }
$$

The explosion curve was found to be practically a parabola, whose equation is-

$$
y=-1.788 x+32.833 \pm V 89+423 x-1588.61
$$

in which

$$
y=\frac{p}{10}, x=100 v \text {. }
$$

The broken lines on Fig. 2 show the curves corresponding 
to the equation, and the following table gives the errors by calculation.

\begin{tabular}{|c|c|c|c|c|c|}
\hline \multicolumn{6}{|c|}{ EXPANSION CURVE. } \\
\hline$v$ & $\stackrel{p}{p}$ from equation. & $\begin{array}{c}p \\
\text { from card. }\end{array}$ & v & $\stackrel{p}{\text { from equation. }}$ & $\begin{array}{c}p \\
\text { from card. }\end{array}$ \\
\hline 23855 & $124^{\circ} 97$ & 123.20 & 32109 & $81 \cdot 52$ & $81 \cdot 39$ \\
\hline .25034 & $116 \cdot 60$ & 117.18 & 33288 & $77 \cdot 41$ & 77.63 \\
\hline .26213 & $109^{\circ}$ II & 110.34 & $\cdot 34467$ & $73^{6} 62$ & $73 \cdot 89$ \\
\hline$\cdot 27392$ & 102.47 & $103^{\circ} 49$ & 35646 & 70.14 & $70 \cdot 15$ \\
\hline $2857 \mathrm{I}$ & 96.44 & $97^{\circ} 03$ & $\cdot 36825$ & 66.97 & $66 \cdot 89$ \\
\hline $2975^{\circ}$ & 90.98 & $91 \cdot 25$ & 38004 & 63.98 & 63.56 \\
\hline 30929 & $86 \cdot 02$ & $86 \cdot 25$ & 39183 & $6 r \cdot 23$ & $59^{\prime} 99$ \\
\hline
\end{tabular}

COMPRESSION CURVE.

\begin{tabular}{|c|c|c|c|c|c|}
\hline$v$ & $\stackrel{p}{p}$ & $\begin{array}{c}p \\
\text { from cavd. }\end{array}$ & 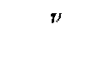 & $\underset{\text { from equation. }}{\phi}$ & $\begin{array}{c}p \\
\text { from card. }\end{array}$ \\
\hline-17960 & $52 \cdot 06$ & $52 \cdot 25$ & $\cdot 25034$ & $3 I \cdot 32$ & $3 I \cdot 4 I$ \\
\hline I $1855^{\circ}$ & $49^{\prime} 55$ & $49^{\circ} 13$ & 26213 & $29^{\circ} 19$ & 29.25 \\
\hline .19139 & $47 \cdot 24$ & $47^{\circ} 08$ & $\cdot 27392$ & $27^{\circ} 29$ & $27^{\prime} 30$ \\
\hline 19729 & $45^{\circ} \circ 9$ & 44.87 & 28571 & $25^{\circ} 5^{8}$ & 25.53 \\
\hline 20318 & $43^{\circ} 10$ & $42^{\prime} 9 \mathrm{I}$ & 29750 & $24^{\circ} 04$ & $239^{1}$ \\
\hline$\cdot 20908$ & $4 I \cdot 26$ & $41 \cdot 27$ & 30929 & 22.65 & $22 \cdot 72$ \\
\hline 21497 & $39^{\circ} 54$ & $39^{60}$ & 32109 & $21 \cdot 39$ & $21 \cdot 46$ \\
\hline 22089 & $37^{\circ} 93$ & $3^{8 \cdot} \cdot 32$ & 33288 & $20 \cdot 24$ & $20^{\prime} 34$ \\
\hline 22676 & 36.43 & 36.94 & 34467 & $19^{\prime} 19$ & $19 \cdot 15$ \\
\hline$\cdot 23266$ & $35^{\circ} \circ 3$ & $35 \cdot 39$ & .35646 & 18.22 & 18.34 \\
\hline 23855 & $33^{\circ} 70$ & $33^{\circ} 94$ & & & \\
\hline
\end{tabular}

EXPLOSION CURVE.

\begin{tabular}{|c|c|c|}
\hline$y$ & p & \\
\hline -1796 & $48 \cdot 90$ & $51 \cdot 25$ \\
\hline 1855 & $80^{\circ} 59$ & $8 \mathrm{r} \circ \mathrm{O}$ \\
\hline 9139 & $97^{\circ} 10$ & $97^{\circ} \mathrm{Or}$ \\
\hline
\end{tabular}

$\begin{array}{ccc}v & p & \\ & \text { from equation. from card. } \\ \cdot 19729 & 108 \cdot 70 & 108 \cdot 70 \\ \cdot 20318 & 116.55 & 116.99 \\ \cdot 20908 & 121.91 & 122.49\end{array}$

HEAT.

From the mean indicator card it was found that the mean pressure was fifty-nine pounds per square inch, and the work performed per explosion was $59 \times$ I $44 \times 2594$ (volume passed through by the piston) $=2203.8$ foot pounds. This is equivalent to-

$$
\frac{2203 \cdot 8}{772}=2 \cdot 854
$$

heat units transformed into work at each explosion.

From the amount and temperature of the jacket water it was found that $46 \mathrm{r}^{\circ} 92$ heat units were carried away per 


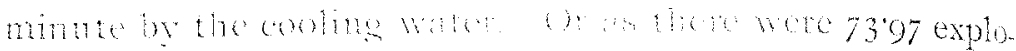
sions thentinte

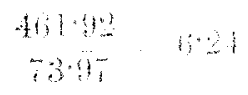

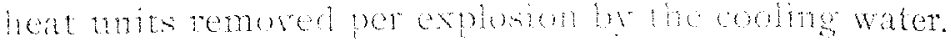

The following gives the restits of the terts of the gas

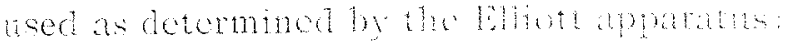
(O)
$\mathrm{CH}$,
30
()
43
r'923
(i)
as
$10^{+} y 20$
$\mathrm{CO}$
$6 \%$
27
279
$\mathrm{CH}$
3197
906
15419
38042
9021
22273

1) and

Ey Wigh

The following are the calculated restitis from these values:

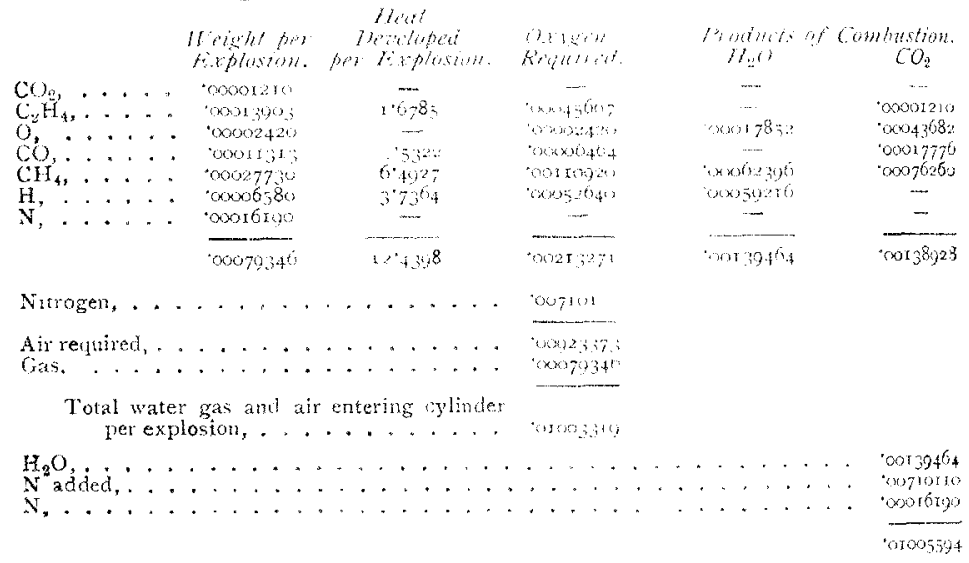

The heat carried off in the products of combustion isthet thits
In $\mathrm{H}_{2} \mathrm{O}$ (steam), . . . . . . . . I ${ }^{\circ} y 291$
$\mathrm{CO}_{2}, .+.+.+. .2149$
$\mathrm{N}, \cdot .+. \cdot \cdot \cdot 2438$
rer. Cert.
Heat carried off in exhaust, . . . . $3+40-\frac{370}{1244}=2793$
Heat converted into work, . . . = $=2.85 \quad=22 \mathrm{gl}$
lieat taken by jacket water,,$=6.24=5016$
Total heat accounted for, . $=\overline{1240} \quad 100^{\circ}$
Total heat received, . . . ..... $12+4$ 


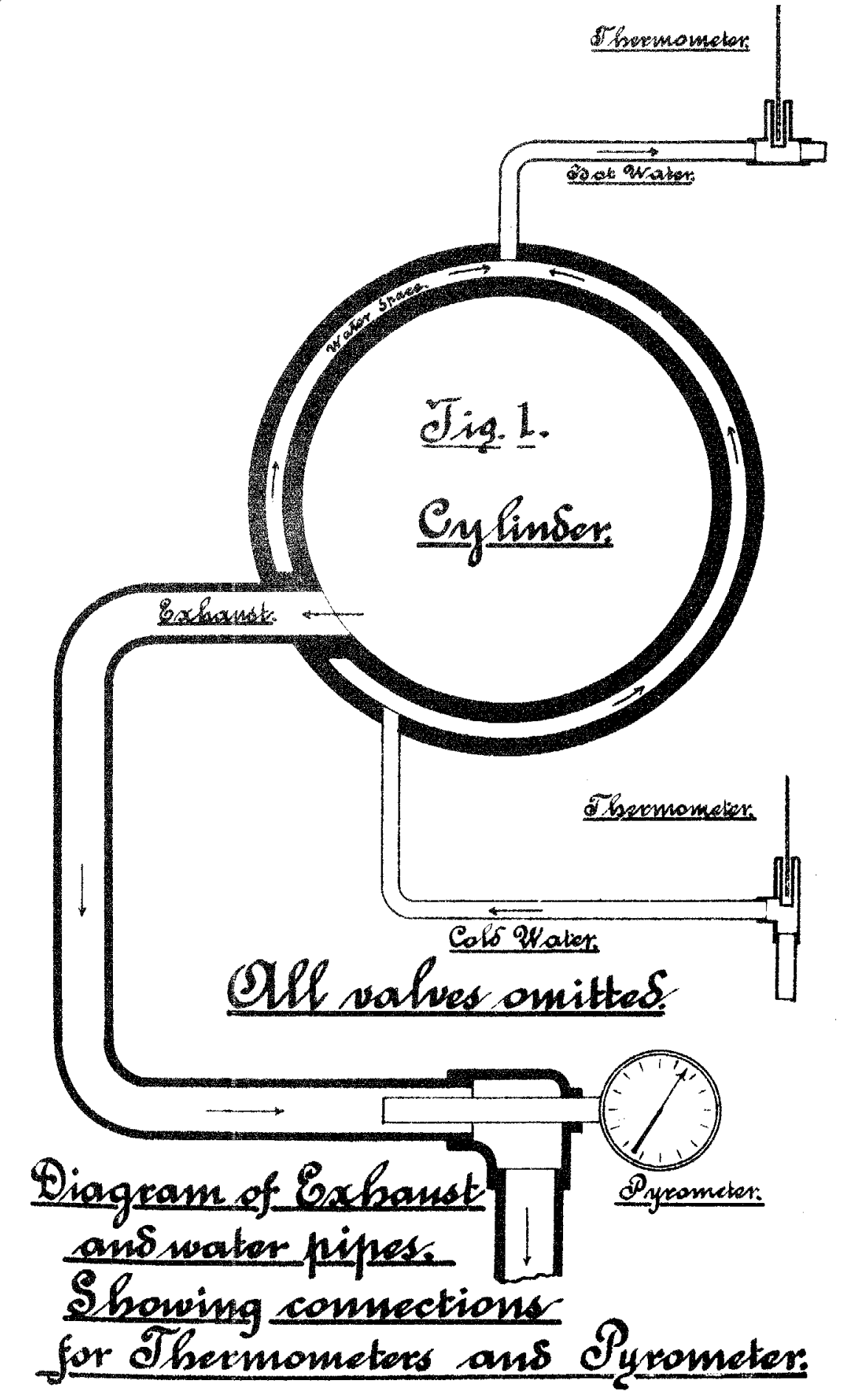




$$
\text { Fe..., }\{, 0 .\}
$$

These calculations are made on the supposition that the ammut of air supplied to the cylinder is just enough to cusc complete combustion, and are given for what they ware worth. That they are, at least to a certain extent, incifiable can be seen from the following:

(6u) $63+6$ pounds of gas oceupying

$$
\frac{334 \cdot 78 \text { (cubic feet, total) }}{14054 \text { (no. explosion) }} \text { cubic feet }
$$

at 62.2 F and a pressure of 14.96 pounds per square inch, requires oc923373 pounds of air to completely burn it.

It is fair to suppose that just before the mixture of gas and air is compressed it has the temperature of the cylinder, which must be about that of the jacket water or $89^{\circ}$. $19 \mathrm{~F}$. The gats oecupies at volume of

$$
\frac{334.78}{14054} \times \underset{521.6}{548.59} \times \frac{14.96}{14.85}=\cdot 02523 \text { cubic feet. }
$$

.00923373 pounds of air at 14.85 pounds per square inch and a temperature of 89.19 occupies 22985 cubic feet. The total volume occupied by the gas and air is therefore 25508 cubic feet. The clearance volume was filled with the products of combustion at this same pressure and temperature before the mixture of gas and air was drawn in. The incoming gas and air should therefore fill a volume equal to the stroke displacement, or 2594 cubic feet, and we have therefore a volume of air $=\cdot 2594-.25508=.00432 \mathrm{cubic}$ feet of air drawn in, but not used, a quantity that we can omit in our calculations. 